University of Nebraska - Lincoln

DigitalCommons@University of Nebraska - Lincoln

Faculty Publications from the Harold W. Manter Laboratory of Parasitology

$12-1985$

\title{
Phylogenetics and the Future of Helminth Systematics
}

Daniel R. Brooks

University of Toronto,dnlbrooks@gmail.com

Follow this and additional works at: https://digitalcommons.unl.edu/parasitologyfacpubs

Part of the Parasitology Commons

Brooks, Daniel R., "Phylogenetics and the Future of Helminth Systematics" (1985). Faculty Publications from the Harold W. Manter Laboratory of Parasitology. 208.

https://digitalcommons.unl.edu/parasitologyfacpubs/208

This Article is brought to you for free and open access by the Parasitology, Harold W. Manter Laboratory of at DigitalCommons@University of Nebraska - Lincoln. It has been accepted for inclusion in Faculty Publications from the Harold W. Manter Laboratory of Parasitology by an authorized administrator of DigitalCommons@University of Nebraska - Lincoln. 


\title{
INVITED REVIEW
}

\section{PHYLOGENETICS AND THE FUTURE OF HELMINTH SYSTEMATICS}

\author{
Daniel R. Brooks \\ Department of Zoology, University of British Columbia, Vancouver, British Columbia, Canada V6T 2A9
}

\begin{abstract}
Phylogenetic systematics is a relatively new formal technique that increases the precision with which one can make direct estimates of the history of phylogenetic descent. These estimates are made in the form of phylogenetic trees, or cladograms. Cladograms may be converted directly into classifications or they may be used to test various hypotheses about the evolutionary process. More than 20 phylogenetic analyses of helminth groups have been published already, and these have been used to investigate evolutionary questions in developmental biology, biogeography, speciation, coevolution, and evolutionary ecology.
\end{abstract}

\section{WHAT IS PHYLOGENETICS?}

In 1965 and 1966, English-speaking biologists were introduced to something called phylogenetic systematics (Hennig, 1965, 1966). The author of this approach, the late German entomologist Willi Hennig, was interested in formulating what he called a "general reference system" for comparative biology. In an earlier work in German, Hennig (1950) had argued two major points. First, he had distinguished between special reference systems and general reference systems in biological classifications. Special reference systems were those constructed to emphasize a particular kind of relationship among different species. For example, a classification that placed all the parasitic helminths inhabiting mammals in one category, those inhabiting birds in another, and so forth, would be a special reference system useful for categorizing helminth faunas in various host groups. It is doubtful that such a classification would be good for much else, since it would place various platyhelminths, nematodes and acanthocephalans together in the same categories. A general reference system, on the other hand, would be one that would provide the most efficient summary of the maximum amount of information about the species being classified. Hennig reasoned that the logical choice for a general reference system in biology would be one based on the genealogical, or phylogenetic, relationships of the species involved. The choice of genealogy was based on two observations: (1) the one attribute of any organism or species that would always be constant was its history, so phylogenetic history should be the most stable cri-

Received 11 December 1984; revised 2 May 1985; accepted 6 May 1985. terion for classifying and (2) genealogical relationships, like classifications, are inherently hierarchical.

The second major point which Hennig (1950) argued had to do with developing a formal general method for discovering phylogenetic relationships. Hennig objected to phylogenetic schemes which were based on hypothetical idealized "archetype" ancestors. He asserted that all species are composites of ancestral and derived traits; therefore, there are no such things as archetypes that, by definition, are all-primitive. This assertion led directly to Hennig's proposed methodology. If the traits exhibited by any species are a combination of primitive and derived features, then the traits shared by two or more species will be indicators of phylogenetic relationship. Shared primitive traits indicate general phylogenetic relationships while shared derived traits indicate more particular phylogenetic relationships. Two species that share a derived trait unique to them are each other's closest relatives.

For example, adult strigeid digeneans have parenchyma-filled bodies; this is a general trait of platyhelminths and indicates in a general sense that strigeids are related to other platyhelminths. Strigeids also have miracidia, initial larval stages found in all digenean species. This indicates that strigeids are related in general to all digeneans. Finally, all strigeids have a structure on the ventral body surface called the tribocytic organ. This organ is found only in cyathocotylid, diplostomatid and strigeid digeneans. This trait tells us that strigeids are related in particular to cyathocotylids and diplostomatids; that is, those three groups are each other's closest relatives.

Note also that, relative to platyhelminths as a group, the fact that strigeids have miracidia is a special trait, but relative to just digeneans, it is 


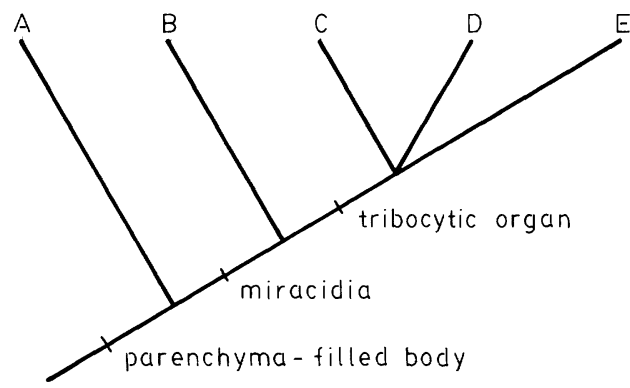

Figure 1. Cladogram of five different platyhelminth taxa, including a "turbellarian" group (A), a generalized digenean group (B), and three strigeiform groups (CDE). Labels next to slash marks on branches name shared traits indicating phylogenetic relationships.

a general trait. Explanation of a trait as general (primitive) or particular (derived) thus depends on the perspective of the particular study. Hennig considered such relative assessments to be more consistent with evolutionary considerations than absolute assessments. Although miracidia are a general trait of all digenean species today, in the distant past they were a unique trait of a single ancestral species. The evolutionary process itself is responsible for the relative nature of assessments of primitive and derived traits. In an attempt to avoid what he felt were ambiguous and absolutist connotations of those terms, Hennig coined two new terms, plesiomorphy (plesionear the source) and apomorphy (apo-away from the source) to refer to relatively primitive and relatively derived traits, respectively. Shared traits thus became symplesiomorphies and synapomorphies. The diagnostic features of each grouping in the genealogical hierarchy would be those traits viewed as apomorphic at the level of that particular grouping. A parenchyma-filled body would be diagnostic of platyhelminths relative to other metazoans but would not be diagnostic of digeneans, even though all digeneans have parenchyma-filled bodies. This is because other platyhelminths have parenchyma-filled bodies as well. In evolutionary terms, the apomorphic traits characterizing each grouping are those traits that first evolved in the common ancestor of the group.

In its simplest form, Hennig's method consists of determining plesiomorphic and apomorphic traits for the various taxa one intends to classify. The taxa are then grouped together according to the apomorphic traits they share. The result is a phylogenetic tree, often called a cladogram (see Fig. 1). The two most critical parts of the method are the determination of plesiomorphic and apomorphic traits and the resolution of conflicting data.

Hennig (1966) listed a number of different ways one could determine whether a trait was plesiomorphic or apomorphic for a given group of taxa. There have been many recent discussions of these ideas, and phylogeneticists seem to have found only two approaches to be consistently sound (see Stevens, 1980 for a review). These are the "outgroup criterion" and the "ontogenetic criterion." The outgroup criterion states that any trait found in at least one member of the group being studied that also occurs in taxa outside the study group is plesiomorphic. Thus, a parenchyma-filled body is plesiomorphic for digeneans because there are non-digeneans which also have parenchyma-filled bodies. Since outgroups evolve themselves, it is often necessary to use more than one outgroup to establish enough apomorphic traits to fully classify a group. The ontogenetic criterion states that, given two organisms with different adult traits, if one organism exhibits the other's adult trait during development, in addition to its own, its adult trait is apomorphic and the other's adult trait is plesiomorphic. This approach is more limited than the outgroup criterion, since it works only for cases in which evolution has proceeded by adding characteristics to the ancestral developmental program (this includes but is not restricted to recapitulation). Substitutions in developmental programs cannot be resolved by the ontogenetic criterion because they are ambiguous, and secondary deletion of steps from developmental programs will be misinterpreted as primitive absence of steps (Brooks and Wiley, 1985).

After determining which traits are apomorphic and which are plesiomorphic, one is sometimes faced with apomorphic traits which suggest conflicting groupings. We know the reason for such conflicts; it is the phenomenon of parallel or convergent evolution, given the general name homoplasy, in contrast with homology. Homologous traits of any taxa all co-vary with the phylogenetic relationships of the taxa; homoplasious traits do not. So long as homoplasious traits do not co-vary in larger numbers than the homologous traits, phylogenetic systematic techniques will pinpoint the proper phylogenetic relationships. The possible occurrence of great amounts of convergent or parallel evolution re- 
quires only that many traits be used in the analysis. An assumption is made that the pattern of relationships indicated by a plurality of the traits examined is the best estimate of phylogenetic relationships. For example, if one looks at only a few traits of the cestodarian platyhelminths (gyrocotylideans, amphilinideans and eucestodes) one might consider the lack of an intestinal tract to indicate relationships with other gutless flatworm groups, such as acoels, rather than with trematodes and rhabdocoels. When 39 different characters are considered together (Brooks et al., 1985a), however, the lack of a gut in these parasitic groups is unambiguously delimited as a convergent trait. Since this requires that large numbers of traits be analyzed together, an increasing number of phylogeneticists have found it helpful to use computer-assisted algorithms to search for the plurality pattern. The most effective algorithms are the so-called "parsimony methods" (e.g., Farris, 1970; Farris et al., 1970a, 1970b) which search for the plurality pattern by minimizing the postulated number of homoplasies. For additional technical information, see Brooks et al. (1984), Wiley (1981a), Nelson ana Platnick (1981), Eldredge and Cracraft (1980), and various articles in Systematic Zoology.

There is a mistaken impression among some systematists that phylogenetics is done in the reverse manner to what I have described. That is, one decides what the groups are, then decides what their phylogenetic relationships are, and finally interprets various characteristics, post hoc, in such a way as to support the phylogeny. It is the contention of phylogeneticists, among others, that no empirical criteria exist for "knowing" a phylogeny in this manner, and inevitably all such discussions rest on appeals to authority rather than to evidence. When such recourse to authority involves one's mentor(s), it is sometimes jokingly termed the "academic outgroup criterion." Phylogenetic systematics is not used to justify arbitrary decisions about evolutionary relationships but as a means of evaluating characters and arriving at decisions about groups and their relationships based on the weight of evidence.

\section{WHAT CAN WE DO WITH PHYLOGENETICS?}

Beckner (1959) stated that systematics has two functions, classification (information storage and retrieval) and implementation of biological theory. Phylogenetics has made significant contributions in both areas.

\section{Classification}

Phylogeneticists are faced with two problems in presenting their results as classifications. First, they wish to make certain that classifications accurately reflect our current state of knowledge about phylogenetic descent. Second, they wish to disrupt existing classifications as little as possible. Rather than recount the lively history of debates about the perceived dangers of phylogenetic classification, much of which took place in the pages of Systematic Zoology, I will discuss the reconciliation promoted most articulately by Wiley (1981a). Consider the phylogenetic tree in Figure 2. Phylogeneticists would allow any classification from which the tree could be directly reconstructed. The most explicit classification would be:

\section{TAXON ABCDE TAXON A TAXON BCDE TAXON B TAXON CDE TAXON C TAXON DE TAXON D TAXON E}

However, if A-E are genera, taxon DE and taxon $\mathrm{C}$ might be subfamilies, taxon $\mathrm{CDE}$ and taxon $\mathrm{B}$ families, taxon BCDE and taxon A superfamilies, and taxon $A B C D E$ a sub-order. This could proliferate higher taxonomic categories to such an extent that the classification would be too unwieldy to use. Wiley (1981a) proposed a "sequencing" convention that states that any taxon in a classification is the sister-group (closest relative) of the taxa of equivalent rank following it. For example, if A-E have traditionally been placed in one subfamily, the sequenced classification could be:

subfamily ABCDE
genus A
genus B
genus C
genus D
genus E

In order to reconstruct the phylogenetic tree, those five genera would have to be listed in the order shown. Genus A is the sister-group of BCDE; B is the sister-group of $\mathrm{CDE}$; and $\mathrm{C}$ is the sistergroup of DE.

Phylogenetic systematic classifications have been provided for the following groups of para- 


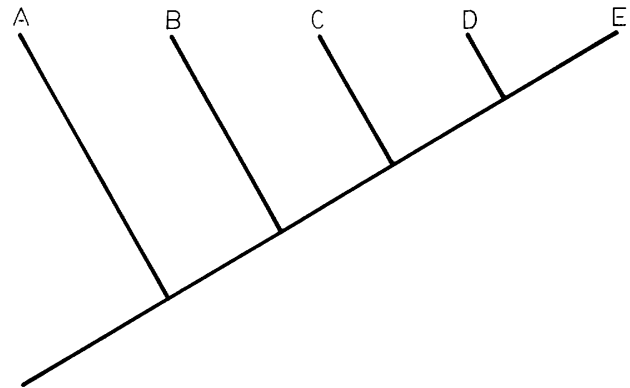

Figure 2. Cladogram for five hypothetical taxa A-E.

sitic helminths: plagiorchiform digeneans of the genus Glypthelmins (Brooks, 1977), the genera of proteocephalidean cestodes (Brooks, 1978; Brooks and Rasmussen, 1985), liolopid digeneans (Brooks and Overstreet, 1978), acanthostomine digeneans (Brooks, 1981a; Brooks and Caira, 1982), some nematodes of the genus Oesophagostomum (Glen and Brooks, 1985), the major groups of parasitic platyhelminths (Brooks, 1982; Brooks et al., 1985a), the families of digeneans (Brooks et al., 1985b), elaphostrongyline nematodes (Platt, 1984), nematodes of the genus Nematodirella (Lichtenfels and Pilitt, 1983), plant cyst nematodes of the family Heteroderidae (Ferris, 1979), and nematodes of the family Leptonchidae (Ferris et al., 1981).

The restriction that classifications must be consistent with the phylogenetic trees from which they are derived is a controversial aspect of phylogenetic systematics. Consider Figure 2 again. Let us suppose that taxa $\mathrm{D}$ and $\mathrm{E}$ are helminths with indirect (multi-host) life cycles, complex developmental programs with discrete larval stages, and have numerous unique morphological traits. Let us further suppose that taxa A, B and C have simple (one-host) life cycles, direct development, and few unique traits. One might be tempted to classify $\mathrm{ABCDE}$ in the following way:

\section{TAXON ABCDE \\ TAXON ABC \\ TAXON A \\ TAXON B \\ TAXON C \\ TAXON DE \\ TAXON D \\ TAXON E}

One could easily justify such a classification by asserting that $\mathrm{ABC}$ and $\mathrm{DE}$ occupy different adaptive zones, or evolutionary "grades," and that a truly evolutionary classification ought to reflect that. On the other hand, there is no way to reconstruct the phylogenetic tree (Fig. 2) from such a classification. Wiley (1981b) has shown that no classification that includes grade groups can be consistent with the phylogeny of the group. In addition, such classifications overestimate the amount of convergent and parallel evolution that has occurred. The apomorphic traits common to $\mathrm{C}$ and to DE in Figure 2 would have to be due to convergent evolution if the taxa are placed in different categories in the classification. One of the maxims of parasitology is that parasites are paradigms of adaptive plasticity; hence, one would expect to find high levels of convergence and parallelism. This notion appears to be an artifact of "gradistic" classifications. A recent phylogenetic analysis of digenean families (Brooks et al., 1985b) showed that less than $25 \%$ of the 213 characters used showed any evidence of convergence or parallelism. Hence, phylogeneticists say, no matter how useful grades might be in pinpointing ecological similarities among taxa, they provide misleading implications about patterns of phylogenetic descent. It is not enough, therefore, to group taxa according to "similarity." One must know whether the similarity is due to a shared plesiomorphic trait $(\mathrm{ABC})$ or a shared apomorphic trait (DE).

\section{Documenting evolutionary patterns}

Phylogenetic trees produced by phylogenetic analysis are explicit direct estimates of historical patterns. As such, they can be used to provide an additional source of evidence for investigations of various evolutionary phenomenon. It is assumed that every hypothesis about evolutionary mechanisms (processes) implies predictions about the expected outcome (patterns) of phylogenetic descent affected by those mechanisms. Thus, phylogenetic trees can be used $a$ priori to restrict the realm of explanations about processes involved in evolution, or can be used a posteriori to test the expected outcome of hypothesized evolutionary processes. Applications of phylogenetics to evolutionaary biology have involved studies in (1) developmental biology, (2) speciation and biogeography, (3) coevolution, and (4) community ecology.

\section{Developmental biology}

There is currently much interest in the relationship between development and evolution. A 
fair amount of this interest involves a renewed appreciation for the work of Richard Goldschmidt (1940), an outstanding helminthologist and evolutionary biologist; for example, Steven J. Gould of Harvard University wrote an essay of appreciation for Goldschmidt in the recent (1982) re-issue of The Material Basis of Evolution. One major topic concerns the phenomenon of heterochrony, or differential rates of development. Fink (1982) devised a rigorous formalism using phylogenetics for detecting various forms of heterochrony in the phylogenesis of any group of species. Helminthology appears to be a treasure-trove of potential studies in this area. For example, we know of no digenean life cycles which include both rediae and daughter sporocysts. Phylogenetic analysis suggests that rediae are plesiomorphic. Are daughter sporocysts unique larval stages favored by natural selection over rediae to such an extent that we never find them together, or are rediae and daughter sporocysts linked developmentally? Brooks et al. (1985b) suggested that if the development of the pharynx and gut were retarded (paedomorphosis) in species having rediae, the resulting rediae would be sacs of germinal cells with a birth pore and no other structure-the definition of a daughter sporocyst! Whether this is due to retarded rate of development (neoteny) or retarded initiation of development (pre-displacement) in each particular case is not known. But this finding from a phylogenetic analysis leads us to look for an explanation in developmental biology rather than in ecology or population biology. A third form of paedomorphosis occurs when the duration of development is retarded (progenesis). For example, during the ontogeny of most plagiorchiform digeneans, the coils of the uterus become more extensive and expand from being only intercecal to having extracecal portions as well. The presence of extracecal loops in the adult is a plesiomorphic trait. And yet, members of two sub-genera of Glypthelmins are characterized by having only intercecal loops as adults. Clearly, the uterine development does not proceed as far in those species. The mechanistic explanation for such occurrence is more likely to be found in developmental biology than in any discussions of the selective value of the relative fecundity of species with "big" and "little" uteri.

A second area of investigation involves the expected relationship between larval and adult traits in evolution. It is clear that whenever evolution proceeds by adding traits at the end of development (recapitulation) larval and adult traits will show the same phylogenetic relationships. But, what if particular stages arose as adaptive responses to selection pressures? Then, as deBeer (1959) pointed out, larvae and adults will show different relationships. Digenean systematics has lived with such a dilemma for over 50 years. Should the classification of digeneans be based on larval (especially cercarial) or adult characters? There have been two schools of thought opposed to each other. Each one thought that either larvae or adults were the adaptive stage and thus inappropriate for classification. A phylogenetic analysis of digeneans (Brooks et al., 1985b) suggested that the larval stages were not recapitulations; thus, they should be the adaptive stage. And yet, data for larvae and data for adults supported the same classification when analyzed phylogenetically. Apparently, there are some inherent developmental constraints on "adaptive response."

Finally, phylogenetic analysis can help us recognize cases in which the same name has been applied to life cycle patterns which evolved in different ways. For example, phylogenetic analysis of the higher groups of parasitic platyhelminths (Brooks et al., 1985a; O'Grady, 1985) indicated that digenean life cycles evolved by the addition of (1) a vertebrate host and of (2) new larval features characterizing development in the primitive molluscan host. Cestode life cycles, on the other hand, evolved by the addition of (1) an invertebrate host and of (2) new adult features characterizing development in the primitive vertebrate host. Thus, the "complex life cycles" of digeneans and of cestodes evolved in almost exactly opposite manners. The one thing common to both cases is that the most conservative part of the developmental program is found in the acquired host type and the innovative part of the developmental program is found in the primitive host type. Those of us who were trained to think in terms of host colonizations leading to morphological change in parasite evolution find such discoveries interesting.

Although we helminthologists often lament the paucity of life cycle studies done in our groups, I suspect that more is known about the ontogenetic pathways of helminths than of many other groups of organisms. That is the reason we can so easily find interesting questions when using the results of phylogenetic analysis to make predictions about undiscovered aspects of evolution and development. 


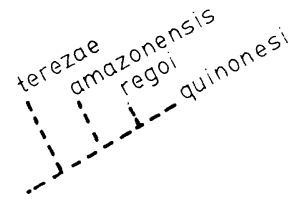

(a)

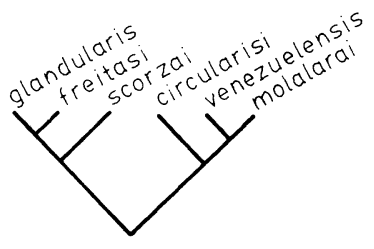

(b)
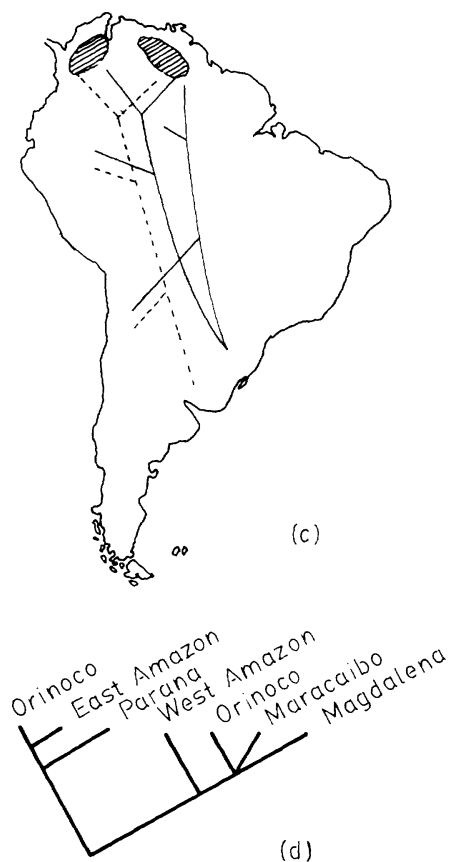

FIGURE 3. Phylogenetics and biogeography. 3a. Cladogram of species of cestode genus Acanthobothrium occurring in freshwater stingrays (redrawn from Brooks et al., 1981). 3b. Cladogram of species of cestode genus Rhinebothroides, all occurring in freshwater stingrays (redrawn and corrected from Brooks et al., 1981). 3c. Map of South America showing geographic distribution patterns for taxa in $3 \mathrm{a}$ and $3 \mathrm{~b}$. 3d. Cladogram showing historical relationships among various South American river systems.

\section{Biogeography and patterns of speciation}

If one places a phylogenetic tree for a group of species on a map of the areas in which the various species occur, there is often a very marked concordance between the biological history of the species and the geological history of the areas (see Fig. 3). Documenting the extent of this historical relationship between areas and species is the province of a relatively new approach to biogeography called vicariance biogeography (see Croizat et al., 1974; Nelson and Platnick, 1981; Cracraft, 1983). Phylogenetic analyses of helminth groups form a significant proportion of the documented cases of such vicariance (Brooks,

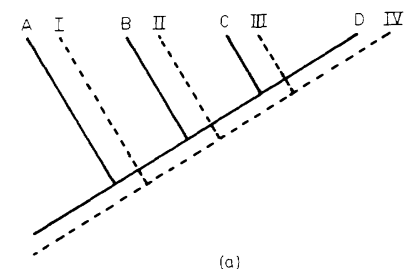

(a)

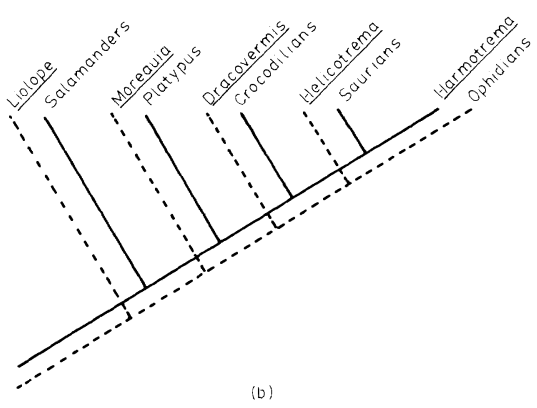

(b)

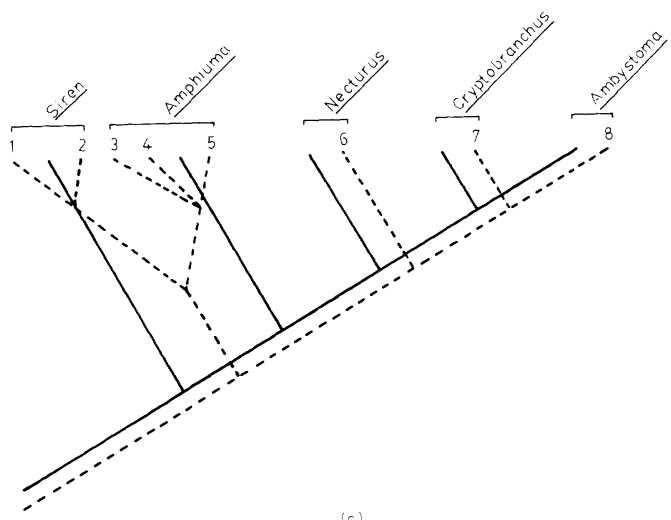

Figure 4. Phylogenetics and coevolution. 4a. Mapping of host (solid lines and letters) and parasite (dotted lines and letters) cladograms. 4b. Genera of the digenean family Liolopidae (dotted lines) and their vertebrate hosts (solid lines). 4c. Species of cestode genus Proteocephalus occurring in North American salamanders (dotted lines) and their amphibian hosts (solid lines). Numbers refer to the following species of Proteocephalus: (1) sireni, (2) aberrans, (3) alternans, (4) amphiumae, (5) amphiumicola, (6) loennbergii, (7), cryptobranchi, and (8) filaroides.

1977, 1978, 1979, 1981a; Brooks and Overstreet, 1978; Brooks et al., 1981). Parasitic helminths with complex life cycles are especially good subjects for such studies because their historical patterns are at least partly a manifestation of the histories of their various host groups. Vicariant patterns shown by parasites thus symbolize vicariant patterns for a variety of different organisms. 
Wiley (1981a) presented a formal methodology designed to use a combination of phylogenetics and biogeography to test speciation models. Thus far, no helminthologist has used this protocol in analyzing speciation patterns.

\section{Coevolution}

Ehrlich and Raven (1964) defined coevolution as an ecological phenomenon, a matter of "stepwise reciprocal response" between any two species with "close and evident" ecological relationships. Parasitologists since von Ihering (1891) have recognized another sense of coevolution; that is, the historical relationship between hosts and parasites, which is often pronounced. And yet, this historical component is missing from almost all assessments of putatively coevolved systems (Brooks, 1979; Mitter and Brooks, 1983; Brooks and Mitter, 1984). Phylogenetics offers a method for documenting the degree to which contemporaneous host-parasite relationships reflect long-standing associations between the host group and the parasite group. The method is analogous to that used in vicariance biogeography (see Fig. 4). Studies in which this methodology has been applied using groups of parasitic helminths include frogs and their intestinal digeneans (Brooks, 1977), crocodilians and their digenean parasites (Brooks, 1979a), freshwater stingrays and their helminth parasites (Brooks et al., 1981), and Great Apes and their helminths (Glen and Brooks, in press). Other phylogenetic analyses of helminths which have examined coevolution at some level include Brooks (1978, 1981a), Brooks and Caira (1982), Brooks and Glen (1982), Brooks and Overstreet (1978), Brooks and Rasmussen (1985), Deardorff et al. (1981), Lichtenfels and Pilitt (1983), and Platt (1984). Platt (1984) was the first to look closely at the possible coevolution of members of a helminth group and their intermediate hosts. The degree of historical relationship in many of these studies has been found to be quite high.

Any parasites that have an historical relationship with their hosts act like homologous traits of their hosts; that is, they co-vary with their host phylogeny. From this notion, Brooks (1981b) developed a formal method for using parasite data to assess host phylogeny independently of any assumptions about degree of coevolution and without needing a host phylogeny. This has allowed helminth parasite data to be used as an independent source of evidence about host phylogeny in three studies. In two of those studies
(Brooks, 1981b: crocodilians and digeneans; Glen and Brooks, in press: Great Apes and helminths), the parasite data produced a host-group phylogenetic tree consistent with those produced using characteristics of the hosts themselves. In the third case (Brooks, 1981b: freshwater stingrays and helminths), the only existing phylogenetic tree for the hosts is the one based on parasite data. A fourth study, using parasitic copepods and their scombrid (mackerel) fish hosts (Cressey et al., 1983) also found good agreement between parasite data and the host phylogeny.

\section{Community ecology}

Parasite faunas represent excellent model systems for studying community ecology. When phylogenetic trees, biogeography and host relationships are known for a variety of parasites inhabiting the same host group, an assessment of the historical aspects of community structure can be made. Of primary concern is the origin of the various ecological life history traits which characterize the interactions among the various members of the community. If ecological traits are treated like any other kind of trait, and are analyzed phylogenetically, one can determine which ecological traits are present in a community because of contemporaneous interactions and which are present because of ancestral conditions. For example, if two species of intestinal helminth inhabit different parts of the gut, is the separation due to competitive exclusion on the part of the contemporaneous species, or is it due to differences in site preference on the part of their ancestors? This approach to explaining the evolution of ecological life history traits has been explored by Brooks (1980) and, combined with biogeography and coevolution, expanded into a research program called historical ecology (Brooks, 1985).

\section{PHYLOGENETICS AND THE FUTURE OF HELMINTH SYSTEMATICS}

In most branches of biology, systematics developed wholly from a tradition of natural history and comparative morphology. Parasitological systematics has developed with a very pronounced influence from medical and veterinary diagnostics, which stresses unique traits and separation of taxa rather than relationships among taxa. Given parasite diversity, this approach has been quite effective and highly productive. Now that our knowledge of parasite diversity is extensive, though far from exhaustive, we are in a 
position to study many questions about relationships. Phylogenetics offers an analytical technique that will aid such studies greatly.

One of the most active areas of biological research today is evolutionary biology. A more unified view of evolution is emerging, one that encompasses previous achievements in population genetics and population ecology and combines them with developmental biology and phylogenetic systematics. This broader explanatory framework will provide a common ground for molecular biologists, organismic biologists and ecologists (see Brooks, 1984, for a brief review; see Campbell, 1982, for a readable summary; see Brooks and Wiley, 1986, for a proposed unified theory of evolution). Systematic helminthology (indeed systematic parasitology), by virtue of its tradition of broad training incorporating taxonomy, ecology and life cycle studies, finds itself in an unparalleled position in the sociology of biology. Our very training programs are tailormade to produce biologists with a broad enough background to assume leadership roles in the new evolutionary biology. Many systematic botanists and systematic entomologists are also broadly trained. It is therefore distressing to realize that the number of such traditional graduate programs in parasitology has declined precipitously in the past decade. In addition, only a handful of those remaining active include these new advances, such as phylogenetics, in their programs. It would indeed be a shame for parasitology to be under-represented in these exciting times.

\section{ACKNOWLEDGMENTS}

I would like to extend my appreciation to Dr. D. F. Mettrick, editor, and to the members of the editorial and consulting board for inviting me to contribute this article. My thanks also to those many parasitologists who have kindly suffered my professional growing pains over the past 12 years. I owe particular debts of gratitude to Janine N. Caira, Ronald A. Campbell, Murray D. Dailey, Donald W. Duszynski, Gerald W. Esch, William F. Font, John C. Holmes, John Janovy, Jr., J. Ralph Lichtenfels, John S. Mackiewicz, Monte A. Mayes, Brent B. Nichol, Robin M. Overstreet, Thomas R. Platt, Mary H. Pritchard, Robert L. Rausch, Gerald D. Schmidt, and Horace W. Stunkard. My thanks also to the Natural Sciences and Engineering Council (NSERC) Population Biology Committee which, in these times of financial hardships, has pro- vided me with a small yearly operating grant to partially defray some research costs.

\section{LITERATURE CITED}

BECKNER, M. 1959. The biological way of thought. Columbia University Press, New York.

BrooKs, D. R. 1977. Evolutionary history of some plagiorchioid trematodes of anurans. Systematic Zoology 26: 277-289.

- 1978. Systematic status of proteocephalid cestodes from reptiles and amphibians in North America with descriptions of three new species. Proceedings of the Helminthological Society of Washington 45: 1-28.

- 1978. Evolutionary history of the cestode order Proteocephalidea. Systematic Zoology 27: 312-323.

- 1979a. Testing hypotheses of evolutionary relationships among parasitic helminths: The digeneans of crocodilians. American Zoologist 19: 1225-1238.

- 1979b. Testing the context and extent of hostparasite coevolution. Systematic Zoology 28: 299307.

- 1980. Allopatric speciation and non-interactive parasite community structure. Systematic Zoology 29: 192-203.

- 1981a. Revision of the Acanthostominae (Digenea: Cryptogonimidae). Zoological Journal of the Linnaean Society 70: 313-382.

-. 1981b. Hennig's parasitological method: A proposed solution. Systematic Zoology 30: 229249.

- 1982. Higher level classification of parasitic platyhelminths and fundamentals of cestode classification. In Parasites-Their world and ours, D. F. Mettrick and S. S. Desser (eds.). Elsevier Biomedical, Amsterdam, pp. 189-193.

- 1984. What's going on in evolution?: A brief guide to some new ideas in evolutionary theory. Canadian Journal of Zoology 61: 2637-2645.

- 1985. Historical ecology: A new approach to study in the evolution of ecological associations. Annals of the Missouri Botanical Garden 72: 660680.

- AND J. N. CaIRA. 1982. Atrophecaecum lobacetabulare sp. n. (Digenea: Cryptogonimidae: Acanthostominae) with discussion of the generic status of Paracanthostomum Fischthal and Kuntz, 1965 and Ateuchocephala Coil and Kuntz, 1960. Proceedings of the Biological Society of Washington 95: 223-231.

,-- , T. R. Platt, and M. H. Pritchard. 1984. Principles and methods of cladistic analysis. A workbook. Special Publication No. 12, of the Museum of Natural History, University of Kansas, Lawrence, Kansas. 92 p.

mates: A case study in coevolution. Proceedings of the Helminthological Society of Washington 49: 76-85.

- M. A. Mayes, and T. B. Thorson. 1981. Systematic review of cestodes infecting freshwater stingrays (Chondrichthyes: Potamotrygonidae) including four new species from Venezuela. Pro- 
ceedings of the Helminthological Society of Washington 48: 43-64.

—, AND C. MitTer. 1984. Analytical basis of coevolution. In Fungus/insect relationships. Perspectives in ecology and evolution, Q. Wheeler and M. Blackwell (eds.). Columbia University Press, New York, pp. 42-53.

- R. T. O'GRADY, AND D. R. GLEN. 1985a. The phylogeny of the Cercomeria Brooks, 1982 (Platyhelminthes). Poceedings of the Helminthological Society of Washington 52: 1-20.

$\longrightarrow,-$ AND $\longrightarrow$ 1985b. Phylogenetic analysis of the Digenea (Platyhelminthes: Cercomeria) with comments on their adaptive radiation. Canadian Journal of Zoology 63: 411-443.

- AND R. M. Overstreet. 1978. The family Liolopidae (Digenea) including a new genus and two new species from crocodilians. International Journal for Parasitology 8: 267-273.

- AND G. RASMUSSEN. 1985. Proteocephalid cestodes from Venezuelan catfish, with a new classification of the Monticelliidae. Proceedings of the Biological Society of Washington 97: 748-760.

-, T. B. Thorson, AND M. A. Mayes. 1981. Freshwater stingrays (Potamotrygonidae) and their helminth parasites: Testing hypotheses of evolution and coevolution. In Advances in cladistics: Proceedings of the First Meeting of the Willi Hennig Society, V. A. Funk and D. R. Brooks (eds.). New York Botanical Garden, New York, pp. 147175.

- AND E. O. WILEY. Ontogeny, systematics and evolution. Cladistics 1: 1-11.

—, AND —. 1986. Evolution as entropy: Toward a unified theory of biology. University of Chicago Press, Chicago.

Campbell, J. 1982. Grammatical man. Simon and Schuster, New York.

Cracraft, J. 1983. Cladistic analysis and vicariance biogeography. American Scientist 71: 273-281.

Cressey, R. F., B. B. Collette, AND J. L. Russo. 1983. Copepods and scombrid fishes: A study in hostparasite relationships. Fisheries Bulletin 81: 227265.

Croizat, L., G. Nelson, and D. E. Rosen. 1974. Centers of origin and related concepts. Systematic Zoology 23: 265-287.

DEARDORFF, T. L., D. R. BROOKS, AND T. B. ThORSON. 1981. Two species of Echinocephalus (Nematoda: Gnathostomidae) from Neotropical stingrays. Journal of Parasitology 67: 433-439.

DEBeER, G. 1959. Embryos and ancestors. Oxford University Press, Oxford.

Ehrlich, R. R., AND P. H. Raven. 1964. Butterflies and plants: A study in coevolution. Evolution 18: 586-608.

EldRedge, N., AND J. CRACraft. 1980. Phylogenetic patterns and the evolutionary process. Columbia University Press, New York.

FARRIS, J. S. 1970. Methods for computing Wagner trees. Systematic Zoology 19: 83-92.

- A. G. KLUGE, AND M. J. ECKARDT. 1970a. A numerical approach to phylogenetic systematics. Systematic Zoology 19: 172-189. 1970b. On predictivity and efficiency. Systematic Zoology 19: 363-372.

FERRIS, V. R. 1979. Cladistic approaches in the study of soil and plant parasitic nematodes. American Zoologist 19: 1195-1215.

- J. M. Ferris, and C. G. Goseco. 1981. Phylogenetic and biogeographic hypotheses in Leptonchidae (Nematoda: Dorylaimida) and a new classification. Proceedings of the Helminthological Society of Washington 48: 163-171.

FINK, W. L. 1982. The conceptual relationship between ontogeny and phylogeny. Paleobiology 8: 254-264.

Glen, D. R., AND D. R. Brooks. 1985. Phylogenetic relationships of some strongylate nematodes of primates. Proceedings of the Helminthological Society of Washington 52: 227-236.

$\longrightarrow$, AND - Parasitological evidence pertaining to the phylogeny of the hominoid primates. Biological Journal of the Linnaean Society (in press).

GolDSCHMIDT, R. 1940. The material basis of evolution. 1982 reprint. Yale University Press, New Haven, Connecticut.

HenNig, W. 1950. Grundzuge einer Theorie der phylogenetischen Systematik. Deutscher Zentralverlag, Berlin.

Hennig, W. 1965. Phylogenetic systematics. Annual Review of Entomology 10: 97-1 16.

HenNig, W. 1966. Phylogenetic systematics. University of Illinois Press, Urbana, Illinois.

Lichtenfels, J. R., AND P. A. PilitT. 1983. Cuticular ridge patterns of Nematodirus (Nematoda: Trichostrongyloidea) parasitic in domestic ruminants of North America, with a key to species. Proceedings of the Helminthological Society of Washington 50: 261-274

Mitter, C., AND D. R. Brooks. 1983. Phylogenetic aspects of coevolution. In Coevolution, D. Fuytuma and M. Slatkin (eds.). Sinauer Associates, New York, pp. 65-98.

Nelson, G., AND N. I. Platnick. 1981. Systematics and biogeography: Cladistics and vicariance. Columbia University Press, New York.

O'Grady, R. T. 1985. Ontogenetic sequences and the phylogenetics of parasitic flatworm life cycles. Cladistics 1: 159-170.

Platt, T. R. 1984. Evolution of the Elaphostrongylinae (Nematoda: Metastrongyloidea: Protostrongylidae) parasites of cervids (Mammalia). Proceedings of the Helminthological Society of Washington 51: 196-204.

SteVens, P. F. 1980 . Evolutionary polarity of character states. Annual Review of Ecology and Systematics 11: 333-358.

VON IHERING, H. 1891. On the ancient relations between New Zealand and South America. Proceedings of the New Zealand Institute 24: 431-445.

WiLeY, E. O. 1981a. Phylogenetics, the theory and practice of phylogenetic systematics. Wiley-Interscience, New York.

- 1981b. Convex groups and consistent classifications. Systematic Botany 6: 346-358. 